\title{
Patient-focussed outcomes in acromegaly
}

\author{
Mirtha Guitelman • Alin Abreu • \\ Ana Laura Espinosa-de-los-Monteros • \\ Moisés Mercado
}

Published online: 20 September 2013

(c) The Author(s) 2013. This article is published with open access at Springerlink.com

\begin{abstract}
Background Health-related quality of life (QoL) is severely impaired in acromegaly due to the physical and psychological consequences of the disease. Pharmacological and surgical treatments, when available, can improve QoL and life expectancy.

Case description A 34-year-old male with uncontrolled acromegaly due to a large and invasive macroadenoma, which could not be resected by transsphenoidal surgery. Over 9 years, he had limited access to pharmacological interventions and persisted with clinically and biochemically active disease, with severe co-morbidities and a poor QoL, which eventually lead to a premature sudden death. Conclusion This case highlights the impact that active acromegaly has when treatment resources are limited. We
\end{abstract}

M. Guitelman

División Endocrinología, Hospital Carlos G. Durand, Buenos Aires, Argentina

A. Abreu

Endocrinología, Centro Médico Imbanaco, Cali, Colombia

A. L. Espinosa-de-los-Monteros

Servicio de Endocrinología, Hospital de Especialidades, Centro

Médico Nacional S.XXI, IMSS, Mexico City, Mexico

M. Mercado

Faculty of Medicine, Universidad Nacional Autónoma de

México, Mexico City, Mexico

M. Mercado ( $\square)$

Endocrine Service, Experimental Endocrinology Unit, Hospital de Especialidades, Centro Médico Nacional Siglo XXI, Instituto Mexicano del Seguro Social, Aristóteles 68 Polanco,

11560 Mexico City, Mexico

e-mail: moises.mercado@endocrinologia.org.mx;

mmercadoa@yahoo.com review the factors contributing to poor QoL in this disease, with special reference to the Latin American scenario.

Keywords Acromegaly · Pituitary $\cdot$ Latin America . GH · IGF-1 · Quality of life · Somatostatin analogs

\section{Introduction}

Health-related quality of life (QoL) is known to be severely impaired in patients with acromegaly [1-3]. Several validated tools have been used to assess QoL in patients with acromegaly, including one disease-specific instrument called the acromegaly quality of life questionnaire (AcroQoL), which involves 22 items concerning the physical dimension of the disease and two separate psychological dimensions connected with appearance and personal relations [4, 5]. Although improvements in QoL can be achieved with pharmacological and surgical interventions, physical and psychological residual morbidity and worse coping strategies can lead to persistently impaired QoL, even in acromegalic patients with long-term biochemical remission [2, 3, 6-11]. As such, QoL considerations in both treated and untreated patients are important for the long-term management of acromegaly. In this article, we provide a brief overview of the factors contributing to poor QoL in acromegaly, with reference to a Latin American case study, and discuss how QoL can be improved.

\section{QoL in active and controlled acromegaly}

The available evidence from both disease-specific and generic QoL tools consistently shows that patients with acromegaly (even those in biochemical remission) have reduced 

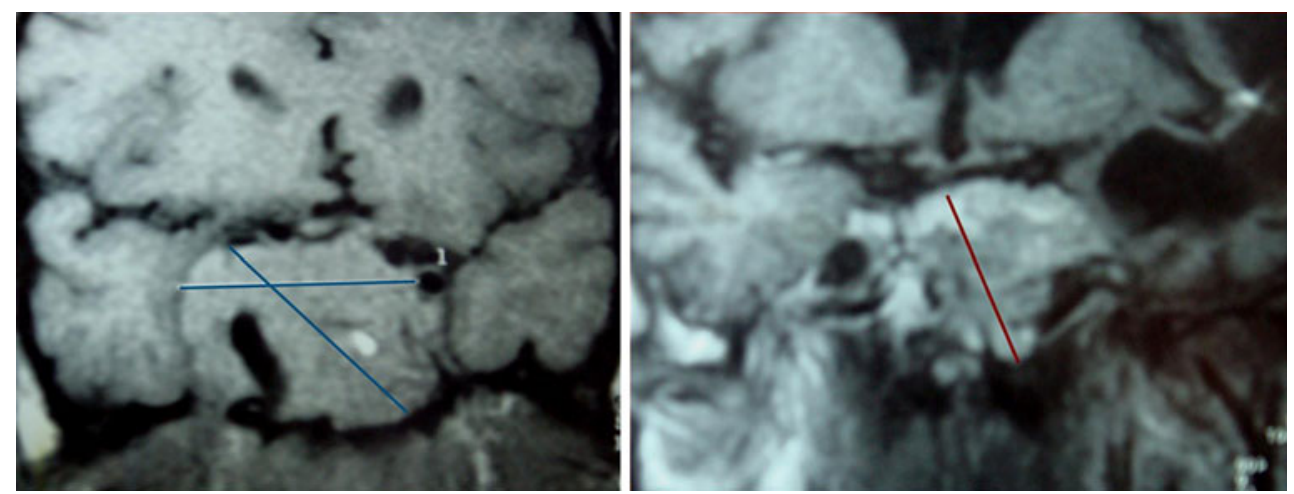

Fig. 1 MRI scans of pituitary tumor at diagnosis (December 1994, left) and 9 years after surgery and radiotherapy without medical treatments (January 2008, right)

QoL compared to matched populations without acromegaly $[1,2,5,6,8,12,13]$. The most affected aspects of QoL in acromegaly are related to appearance and the least affected are related to personal relations $[2,5,14]$.

Several factors appear to predict worse QoL in acromegaly, including disease activity, female gender, older age, longer disease duration, the presence of specific symptoms/comorbidities, certain treatment modalities and delays in diagnosis [2, 5-7, 15]. In terms of disease activity, some (but not all) studies have shown that patients in biochemical remission have significantly better QoL (at least in some dimensions) than patients with persistent disease, or that improvements in biochemical parameters correlate with improved QoL [1, 5, 8, 11, 12, 14, 16-19]. However, it should also be noted that patients with acromegaly who develop growth hormone deficiency $(\mathrm{GH})$ after treatment also have decreased QoL [20].

Several disease-specific symptoms or comorbidities of acromegaly are associated with poor QoL. Joint-related complications (leading to pain and immobility), in particular, are frequently encountered in acromegaly and have been shown to have a significant negative impact on $\mathrm{QoL}$ [7, 21-25]. These complications may persist during biochemical remission and represent a major cause of morbidity [7, 23, 24]. Sleep apnea syndrome is another common complication of acromegaly that has a negative influence on QoL $[11,26]$. Other comorbidities such as depressive mood and hypertension may also be associated with poor QoL in acromegaly [11,22].

Among treatment modalities, radiotherapy in particular has been associated with reduced QoL [7, 27]. In one study that followed patients with stable biochemical control over 4 years, previous radiotherapy was the predominant predictor of progressive impairments in QoL [27]. This may relate to the effects of GH deficiency, among other deficiencies, that can occur with definitive therapy for acromegaly using irradiation or surgery $[3,20]$.
Case study: 9 years of uncontrolled disease without appropriate medical therapy: a case for poor QoL (Mirtha Guitelman, MD)

A 34-year old man presented with headaches, acral enlargement, oily skin, sleep apnea, fatigue, hyperhidrosis and generalized joint pain

All these symptoms started 5 years prior to the first consultation The patient had no relevant background

Physical exam revealed

Thyroid: $30 \mathrm{~g}$

Typical facial features: lip, nose and tongue enlargement

Prognathism

Acral enlargement (finger size: 33)

No Hypertension

Endocrinological lab results (Nov 1993)

Baseline and post-glucose $\mathrm{GH} 50 \mu \mathrm{g} / \mathrm{L}$

IGF-1: $700 \mu \mathrm{g} / \mathrm{L}$ (normal for age $\leq 500 \mu \mathrm{g} / \mathrm{L}$ )

Prolactin: $200 \mu \mathrm{g} / \mathrm{L}$ (normal 5-20 $\mu \mathrm{g} / \mathrm{L}$ )

Total T4: $1.2 \mathrm{nmol} / \mathrm{L}(6.9 \mu \mathrm{g} / \mathrm{dL})$; TSH: $1.6 \mathrm{mIU} / \mathrm{L}$

Testosterone: $6.6 \mathrm{nmol} / \mathrm{L}(190 \mathrm{ng} / \mathrm{dL})$

LH: 3 IU/L; FSH: 2.8 IU/L

Normal glucose metabolism

MRI at diagnosis (Dec 1994)

Voluminous sellar mass with sphenoid sinus invasion, extension in the suprasellar cistern causing displacement of the pituitary stalk and invasion into the right cavernous sinus (Fig. 1)

Complementary studies

Echocardiogram: Mild dilated left ventricle with appropriate systolic function. Left and right ventricular dilatation

Treatments

In 1995 he received intermittently subcutaneous SSAs $300 \mu \mathrm{g} /$ day and bromocriptine for 6 months with no changes in IGF-1 levels or tumor size

Due to the lack of drug availability and lack of response, the patient was sent to surgery

Transsphenoidal surgery (Aug 1996)

Pathology: GH-Prolactin co-secreting tumor

GH after surgery: $51 \mu \mathrm{g} / \mathrm{L}$ 


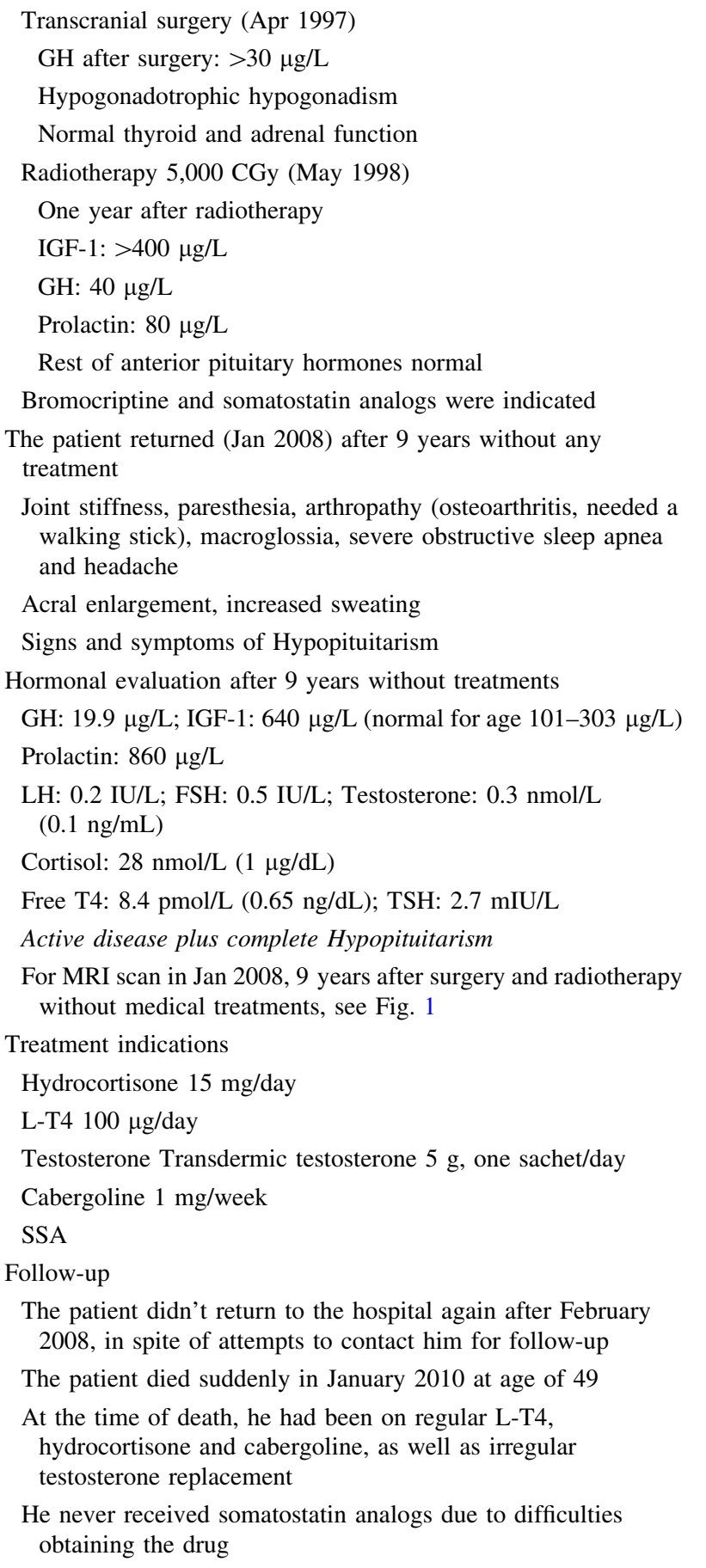

\section{Case discussion}

This 49-year-old man with acromegaly diagnosed at age 34 , never achieved normal levels of IGF-1 and GH despite two surgeries and radiotherapy after initially receiving suboptimal pharmacological therapy. He subsequently received no treatment at all over a period of 9 years followed by further suboptimal pharmacological therapy and died early due to lack of disease control. Patients with acromegaly have significantly increased mortality, even after transsphenoidal surgery [28]. However, achievement of biochemical control has been shown to significantly improve life expectancy [29].

Apart from the patient's reduced life span another important aspect of the patient's poor disease control was the severe debilitating complications of acromegaly that he had to endure for many years. As a consequence, it is highly likely that this patient experienced profound longterm impairments in QoL derived from his multiple systemic complications. The presence of severe arthropathy, in particular, is known to be a major cause of morbidity and immobility in acromegaly and has a marked negative impact on QoL [24, 25]. Other factors, such as sleep apnea and psychological aspects associated with his acromegalic appearance may also have reduced the patient's QoL. The patient is also an illustrative example of the consequences of a delayed diagnosis; had his condition been detected earlier, he would have undoubtedly had a different and better outcome.

Due to the invasive nature of this patient's tumor, pharmacological therapy with SSAs would have been the primary treatment of choice, but these agents were only available intermittently for a short period after diagnosis and this option could not be implemented appropriately. The question is whether long-term pharmacological treatment with SSAs or other pharmacological therapies could have changed the QoL of this patient, as well as improving his life expectancy.

\section{Improving QoL in acromegaly}

As noted above, there is some evidence to suggest that patients with biochemically controlled acromegaly have significantly better QoL (at least on some subscales) than patients with persistent disease, although not all studies have found a strong association [1, 5, 8, 11, 12, 14, 16-19]. One study suggests that the best QoL in treated patients seems to be achieved if insulin-like growth factor-1 (IGF1 ) is normalized and the GH nadir (during an oral glucose tolerance test) is targeted to levels less than $1.0 \mu \mathrm{g} / \mathrm{L}$ but above $0.3 \mu \mathrm{g} / \mathrm{L}[8]$.

Several studies have also shown consistently that treatment with surgery or long-acting SSAs is associated with significant improvements in QoL [30-35]. This might be expected, as these treatments can provide significant improvements in symptoms known to be associated with poor QoL, especially in the frequency and severity of sleep apnea episodes [26]. With the exception of radiotherapy, which is generally associated with poorer QoL, it is hard to distinguish any notable differences on overall QoL between different treatment modalities [14]. Randomized 
comparative studies in newly diagnosed patients suggest that long-acting SSAs and surgery provide similar levels of QoL when used as first-line therapy [32, 35]. Pharmacological combination therapy (e.g., adding pegvisomant to an SSA) may also provide better improvements in QoL independently of having better biochemical control [36].

It should be emphasized that, although clinically and biochemically effective, some SSAs need to be injected by a properly trained professional, and thus, patients are required to visit the hospital or medical office every few weeks. Although usually not a major problem, this may generate more psychological distress, social fears and a poorer sense of well-being and may hamper improvements in QoL [17, 37]. Clinical trial and observational study evidence suggests that patients prefer the option to administer SSAs themselves or by a partner at home rather than by a healthcare professional, and this does not appear to compromise efficacy or safety [38-42]. Further evidence also suggests that patients also prefer longer intervals between injections, and this also appears to be achievable with certain SSAs without loss of efficacy [41, 43].

It has been suggested that targeted psychosocial interventions, such as cognitive behavioral therapy, self-management training, and information on the negative effects of the disease might help biochemically controlled patients with acromegaly to use more active coping strategies, which might lead to improvements in QoL [10]. In a recent study, greater diagnostic delay by the physician (relative to a patient first seeking medical advice) was associated with reduced psychological QoL, depression, sleep disturbances and impaired body image, suggesting that improved physician awareness of acromegaly (leading to earlier diagnosis) may also help to improve QoL [15]. To our knowledge only one Latin-American study has evaluated QoL in acromegaly using an adapted version of the AcrQoL questionnaire [46]. This study from a tertiary care center in Mexico City found that the 50 patients with acromegaly have reduced scores in all scales of the AcroQol (physical, psychological, appearance and interpersonal relationships) when compared to controls [46]; yet, no differences in any of these scales were found between active and controlled patients, perhaps due to the relatively low number of patients [46].

\section{Conclusions}

Patients with long-term uncontrolled acromegaly, as in our case study, are likely to have severe acromegalic features, symptoms and comorbidities and consequently significantly impaired QoL and reduced life expectancy. However, there are many unanswered questions about the benefits of controlled compared with uncontrolled acromegaly regarding QoL and other factors, such as costs and morbidities [14, 19]. For instance, normalization of levels of IGF-1 and GH do not necessarily reflect optimal QoL or symptom relief [44]. As such, QoL considerations in both treated and untreated patients are important for the long-term management of acromegaly and it has been suggested that simplified measures of QoL may provide a reliable additional measurement of disease activity in everyday clinical practice [44].

It is also possible that reduction in tumor mass (which may be independent of biochemical control with SSAs [45]) has the potential to improve QoL, although this remains to be further investigated. With the available evidence it is hard to distinguish any notable consistent differences in QoL between pharmacological therapy and surgery (at least in the first-line setting), whereas radiotherapy appears to be associated with a reduced QoL [14, 32, 35]. However, some factors associated with pharmacological therapy, such as regular hospital visits for drug administration, may have an adverse impact on QoL, and there is the potential to minimize this through the use of drug formulations that require less frequent dosing and/or can be administered at home without the help of a healthcare professional. Longer-acting drugs may also have the potential to improve QoL through tumor shrinkage. Prompt diagnosis and targeted psychosocial interventions may also be an important factors leading to better QoL.

In summary, in patients with active acromegaly, as well as those in remission, attention to QoL issues is highly recommended [3]. The best balance of efficacy, cost and QoL will likely be achieved with an individualized approach to therapy, based on available pharmacological, surgical and radiotherapeutic resources [14].

Acknowledgments The Latin American Knowledge Network Initiative, including meetings and preparation of this supplement, was organized and funded by Ipsen. Medical writing support was provided by Patrick Covernton on behalf of Arsenal-CDM Paris and funded by Ipsen. The authors were fully responsible for the concept and all content, were involved at all stages of manuscript development, and provided approval of the final version for submission.

Open Access This article is distributed under the terms of the Creative Commons Attribution License which permits any use, distribution, and reproduction in any medium, provided the original author(s) and the source are credited.

\section{References}

1. Rowles SV, Prieto L, Badia X, Shalet SM, Webb SM, Trainer PJ (2005) Quality of life (QOL) in patients with acromegaly is severely impaired: use of a novel measure of QOL: acromegaly quality of life questionnaire. J Clin Endocrinol Metab 90(6):3337-3341 
2. Webb SM (2006) Quality of life in acromegaly. Neuroendocrinology 83(3-4):224-229

3. Katznelson L, Atkinson JL, Cook DM, Ezzat SZ, Hamrahian AH, Miller KK, American Association of Clinical Endocrinologists (2011) American Association of Clinical Endocrinologists medical guidelines for clinical practice for the diagnosis and treatment of acromegaly-2011 update. Endocr Pract 17(Suppl 4): $1-44$

4. Webb SM, Prieto L, Badia X, Albareda M, Catalá M, Gaztambide S, Lucas T, Páramo C, Picó A, Lucas A, Halperin I, Obiols G, Astorga R (2002) Acromegaly Quality of Life Questionnaire (ACROQOL) a new health-related quality of life questionnaire for patients with acromegaly: development and psychometric properties. Clin Endocrinol (Oxf) 57(2):251-258

5. Webb SM, Badia X, Surinach NL; Spanish AcroQol Study Group (2006) Validity and clinical applicability of the acromegaly quality of life questionnaire, AcroQoL: a 6-month prospective study. Eur J Endocrinol 155(2):269-277

6. Biermasz NR, van Thiel SW, Pereira AM, Hoftijzer HC, van Hemert AM, Smit JW, Romijn JA, Roelfsema F (2004) Decreased quality of life in patients with acromegaly despite long-term cure of growth hormone excess. J Clin Endocrinol Metab 89(11):5369-5376

7. Biermasz NR, Pereira AM, Smit JW, Romijn JA, Roelfsema F (2005) Morbidity after long-term remission for acromegaly: persisting joint-related complaints cause reduced quality of life. J Clin Endocrinol Metab 90(5):2731-2739

8. Kauppinen-Mäkelin R, Sane T, Sintonen H, Markkanen H, Välimäki MJ, Löyttyniemi E, Niskanen L, Reunanen A, Stenman UH (2006) Quality of life in treated patients with acromegaly. J Clin Endocrinol Metab 91(10):3891-3896

9. Webb SM (2011) Pituitary tumors: coping with 'cured' pituitary tumors. Nat Rev Endocrinol 7(5):251-252

10. Tiemensma J, Kaptein AA, Pereira AM, Smit JW, Romijn JA, Biermasz NR (2011) Coping strategies in patients after treatment for functioning or nonfunctioning pituitary adenomas. J Clin Endocrinol Metab 96(4):964-971

11. Celik O, Kadioglu P (2013) Quality of life in female patients with acromegaly. J Endocrinol Invest 36:412-416

12. T'Sjoen G, Bex M, Maiter D, Velkeniers B, Abs R (2007) Healthrelated quality of life in acromegalic subjects: data from AcroBel, the Belgian registry on acromegaly. Eur J Endocrinol 157(4): 411-417

13. van der Klaauw AA, Kars M, Biermasz NR, Roelfsema F, Dekkers OM, Corssmit EP, van Aken MO, Havekes B, Pereira AM, Pijl H, Smit JW, Romijn JA (2008) Disease-specific impairments in quality of life during long-term follow-up of patients with different pituitary adenomas. Clin Endocrinol (Oxf) 69(5):775-784

14. Marko NF, Lasota E, Hamrahian AH, Weil RJ (2012) Comparative effectiveness review of treatment options for pituitary microadenomas in acromegaly. J Neurosurg 117(3):522-538

15. Siegel S, Streetz-van der Werf C, Schott JS, Nolte K, Karges W, Kreitschmann-Andermahr I (2012) Diagnostic delay is associated with psychosocial impairment in acromegaly. Pituitary. doi: 10 . 1007/s11102-012-0447-z

16. Trepp R, Everts R, Stettler C, Fischli S, Allemann S, Webb SM, Christ ER (2005) Assessment of quality of life in patients with uncontrolled vs. controlled acromegaly using the Acromegaly Quality of Life Questionnaire (AcroQoL). Clin Endocrinol (Oxf) 63(1):103-110

17. Hua SC, Yan YH, Chang TC (2006) Associations of remission status and lanreotide treatment with quality of life in patients with treated acromegaly. Eur J Endocrinol 155(6):831-837

18. Matta MP, Couture E, Cazals L, Vezzosi D, Bennet A, Caron P (2008) Impaired quality of life of patients with acromegaly: control of GH/IGF-I excess improves psychological subscale appearance. Eur J Endocrinol 158(3):305-310

19. Ben-Shlomo A, Sheppard MC, Stephens JM, Pulgar S, Melmed S (2011) Clinical, quality of life, and economic value of acromegaly disease control. Pituitary 14(3):284-294

20. Wexler T, Gunnell L, Omer Z, Kuhlthau K, Beauregard C, Graham G, Utz AL, Biller B, Nachtigall L, Loeffler J, Swearingen B, Klibanski A, Miller KK (2009) Growth hormone deficiency is associated with decreased quality of life in patients with prior acromegaly. J Clin Endocrinol Metab 94(7):2471-2477

21. Miller A, Doll H, David J, Wass J (2008) Impact of musculoskeletal disease on quality of life in long-standing acromegaly. Eur J Endocrinol 158(5):587-593

22. Psaras T, Honegger J, Gallwitz B, Milian M (2011) Are there gender-specific differences concerning quality of life in treated acromegalic patients? Exp Clin Endocrinol Diabetes 119(5): 300-305

23. Wassenaar MJ, Biermasz NR, Kloppenburg M, van der Klaauw AA, Tiemensma J, Smit JW, Pereira AM, Roelfsema F, Kroon HM, Romijn JA (2010) Clinical osteoarthritis predicts physical and psychological QoL in acromegaly patients. Growth Horm IGF Res 20(3):226-233

24. Killinger Z, Kužma M, Sterančáková L, Payer J (2012) Osteoarticular changes in acromegaly. Int J Endocrinol 2012:839282

25. Orük G, Tarhan F, Argin M, Ozmen M (2013) Is every joint symptom related to acromegaly? Endocrine 43(2):404-411

26. Davì MV, Giustina A (2012) Sleep apnea in acromegaly: a review on prevalence, pathogenetic aspects and treatment. Expert Rev Endocrinol Metab 7(1):55-62

27. van der Klaauw AA, Biermasz NR, Hoftijzer HC, Pereira AM, Romijn JA (2008) Previous radiotherapy negatively influences quality of life during 4 years of follow-up in patients cured from acromegaly. Clin Endocrinol (Oxf) 69(1):123-128

28. Dekkers OM, Biermasz NR, Pereira AM, Romijn JA, Vandenbroucke JP (2008) Mortality in acromegaly: a metaanalysis. J Clin Endocrinol Metab 93(1):61-67

29. Holdaway IM, Rajasoorya RC, Gamble GD (2004) Factors influencing mortality in acromegaly. J Clin Endocrinol Metab 89(2):667-674

30. Sonino N, Scarpa E, Paoletta A, Fallo F, Boscaro M (1999) Slowrelease lanreotide treatment in acromegaly: effects on quality of life. Psychother Psychosom 68(3):165-167

31. Gilbert J, Ketchen M, Kane P, Mason T, Baister E, Monaghan M, Barr S, Harris PE (2003) The treatment of de novo acromegalic patients with octreotide-LAR: efficacy, tolerability and cardiovascular effects. Pituitary 6(1):11-18

32. Colao A, Cappabianca P, Caron P, De Menis E, Farrall AJ, Gadelha MR, Hmissi A, Rees A, Reincke M, Safari M, T'Sjoen G, Bouterfa H, Cuneo RC (2009) Octreotide LAR vs. surgery in newly diagnosed patients with acromegaly: a randomized, openlabel, multicentre study. Clin Endocrinol (Oxf) 70(5):757-768

33. Lombardi G, Minuto F, Tamburrano G, Ambrosio MR, Arnaldi G, Arosio M, Chiarini V, Cozzi R, Grottoli S, Mantero F, Bogazzi F, Terzolo M, Tita P, Boscani PF, Colao A (2009) Efficacy of the new long-acting formulation of lanreotide (lanreotide Autogel) in somatostatin analogue-naive patients with acromegaly. J Endocrinol Invest 32(3):202-209

34. Sardella C, Lombardi M, Rossi G, Cosci C, Brogioni S, Scattina I, Webb SM, Gasperi M, Martino E, Bogazzi F (2010) Short- and long-term changes of quality of life in patients with acromegaly: results from a prospective study. J Endocrinol Invest 33(1):20-25

35. Karaca Z, Tanriverdi F, Elbuken G, Cakir I, Donmez H, Selcuklu A, Durak AC, Dokmetas HS, Colak R, Unluhizarci K, Kelestimur F (2011) Comparison of primary octreotide-lar and surgical treatment in newly diagnosed patients with acromegaly. Clin Endocrinol (Oxf) 75(5):678-684 
36. Neggers SJ, van Aken MO, de Herder WW, Feelders RA, Janssen JA, Badia X, Webb SM, van der Lely AJ (2008) Quality of life in acromegalic patients during long-term somatostatin analog treatment with and without pegvisomant. J Clin Endocrinol Metab 93(10):3853-3859

37. Postma MR, Netea-Maier RT, van den Berg G, Homan J, Sluiter WJ, Wagenmakers MA, van den Bergh AC, Wolffenbuttel BH, Hermus AR, van Beek AP (2012) Quality of life is impaired in association with the need for prolonged postoperative therapy by somatostatin analogs in patients with acromegaly. Eur J Endocrinol 166(4):585-592

38. Bevan JS, Newell-Price J, Wass JA, Atkin SL, Bouloux PM, Chapman J, Davis JR, Howlett TA, Randeva HS, Stewart PM, Viswanath A (2008) Home administration of lanreotide Autogel by patients with acromegaly, or their partners, is safe and effective. Clin Endocrinol (Oxf) 68(3):343-349

39. Salvatori R, Nachtigall LB, Cook DM, Bonert V, Molitch ME, Blethen S, Chang S, SALSA Study Group (2010) Effectiveness of self- or partner-administration of an extended-release aqueous-gel formulation of lanreotide in lanreotide-naïve patients with acromegaly. Pituitary 13(2):115-122

40. Salvatori R, Woodmansee WW, Molitch M, Gordon MB, Lomax KG (2013) Lanreotide extended-release aqueous-gel formulation, injected by patient, partner or healthcare provider in patients with acromegaly in the United States: 1-year data from the SODA registry. Pituitary. doi:10.1007/s11102-012-0460-2
41. Carmichael JD (2012) Lanreotide depot deep subcutaneous injection: a new method of delivery and its associated benefits. Patient Prefer Adherence 6:73-82

42. Johanson V, Wilson B, Abrahamsson A, Jianu C, Calissendorff J, Wall N, Grønbæk H, Florholmen J, Ohberg A, Granberg D (2012) Randomized crossover study in patients with neuroendocrine tumors to assess patient preference for lanreotide Autogel $\left({ }^{\circledR}\right)$ given by either self/partner or a health care professional. Patient Prefer Adherence 6:703-710

43. Schopohl J, Strasburger CJ, Caird D, Badenhoop K, Beuschlein F, Droste M, Plöckinger U, Petersenn S, German Lanreotide Study Group (2011) Efficacy and acceptability of lanreotide Autogel ${ }^{\circledR} 120 \mathrm{mg}$ at different dose intervals in patients with acromegaly previously treated with octreotide LAR. Exp Clin Endocrinol Diabetes 119(3):156-162

44. Neggers SJ, Biermasz NR, van der Lely AJ (2012) What is active acromegaly and which parameters do we have? Clin Endocrinol (Oxf) 76(5):609-614

45. Bevan JS (2005) Clinical review: the antitumoral effects of somatostatin analog therapy in acromegaly. J Clin Endocrinol Metab 90(3):1856-1863

46. Garduño-Perez AA, Zamarripa-Escobedo R, Vergara-Lopez A, Guillen-Gonzalez MA, Escudero-Licona I (2011) Análisis de la calidad de vida en pacientes con acromegalia en el Centro Medico Nacional 20 de Noviembre, ISSSTE. Rev Endocrinol Nutr 19:97-101 